J. Nonlinear Var. Anal. 2 (2018), No. 1, pp. 1

Available online at http://jnva.biemdas.com

https://doi.org/10.23952/jnva.2.2018.1.01

\title{
A SPECIAL ISSUE ON NONLINEAR ANALYSIS AND OPTIMIZATION DEDICATED TO PROFESSOR SIMEON REICH, PART I
}

This Special Issue on Nonlinear Analysis and Optimization is dedicated to Professor Simeon Reich in celebration of his 70th birthday. During his research career Professor Reich has made significant contributions to many areas of mathematics including nonlinear operator theory, nonlinear evolution and integral equations, the identification and estimation of nonlinear distributed parameter systems, infinitedimensional holomorphy, variational inequalities, and sequential and parallel algorithms in feasibility and optimization. His list of publications contains three monographs, nineteen edited volumes and more than 450 research papers. His work has had great impact on research in analysis and optimization, as well as on a wide range of their applications. Simeon has had fifteen PhD students and nine MSc students. In this special issue we present papers authored by a selected group of experts in the areas of nonlinear analysis and optimization theory. Most of the papers collected here have been contributed by collaborators, friends and colleagues of Simeon's, who were influenced by his research. Part I of the special issue contains eight papers contributed by well-known experts in nonlinear analysis and optimization from Germany, Greece, Israel, Italy, Poland, Portugal, Romania, Spain and USA. These papers cover a wide spectrum of important problems and topics of current research interest of analysis and optimization such as strongly nonlinear second order multivalued Dirichlet systems, nonlinear fractional initial value problems involving Caputo derivatives, fixed point properties of nonlinear mappings, extragradient methods for solving variational inequalities, time delay systems with a high gain control, intersection properties and hyperconvexity.

Therefore we feel that this special issue will be very valuable for many mathematicians and practitioners who are interested in recent developments in nonlinear analysis and optimization as well as their numerous applications.

Alexander J. Zaslavski

The Technion-Israel Institute of Technology

E-mail address: ajzasl@tx.technion.ac.il

(C) 2018 Journal of Nonlinear and Variational Analysis 